\title{
Assessment the knowledge of mothers regarding Diarrhea of Children less than five years at Internally Displaced Persons (IDPs) Arbit camp: A descriptive study
}

\author{
Layla Abdulkhalk Abas \\ Department of Nursing \\ Sulaimani Polytechnic University \\ Kurdistan Region, Iraq \\ abaslayla@yahoo.com
IbrahimTofiqAhmed
Head of planning department,
Preventive Directorate
Kurdistan Region, Iraq
ibrahim972@yahoo.com

\author{
Attallah Omer Kasem \\ Department of Community health, \\ Sulaimani Polytechnic University, \\ Kurdistan Region, Iraq \\ atta,kasem@sup.edu.iq \\ Rozhgar Abdulla Saleem \\ Head of Primary Health Care \\ Preventive Directorate \\ Kurdistan Region, Iraq \\ Rizhgar.saleem@gmil.com
}

\author{
Shahow AbdulrahmanEzzaddin \\ Department of Community Medicine \\ Sulaimani Medicine University \\ Kurdistan Region, Iraq \\ shahoae67@yahoo.com
Awaz Kamal Maulud
Head of Children Nutrition Preventive Directorate
Kurdistan Region, Iraq
awazk.maulud@yahoo.com

\begin{abstract}
Diarrhea is the $2^{\text {nd }}$ chief reason of child death widespread. Low-and middle-income countries are especially exhausting with this both avoidable and treatable condition. Aim: To investigate how children's health less than five years affected by diarrhea at Internally Displaced Persons (IDPs) in Arbit camp. This study was carried out from december $22^{\text {th }} 2015$ to march 20 2016. Non-probability sampling a convenience sample of (103) mothers of internally Displaced Persons (IDPs) Arbit camp were selected for the purpose of the study. It was comprised of two parts; the first part includes the mothers' demographic attributes and the second part assessed the knowledge of diarrhea with (20) yes or on questions. The main results obtained from the study are as follows, more than the half (54.40\%) of mothers are (18-25) years old, the (49.50\%) of mothers have moderate Socioeconomic status, $(99.00 \%$ of mothers are housewife, also $(54.40 \%)$ of the mothers have one child less than five years. The (46.60\%) of mothers are illiterate and only (32.00\%) of husband read and write and According to the family size of the study (51.50\%) of mothers has five children. About the distance of water sources (56.30\%) of mothers needs more than 5 minutes to reach water sources, $(47.60 \%)$ of them have received health education regarding diarrhea held in primary health care center. There was statistically significant relationship between mother's knowledge of diarrhea and (age group, educational level of husband, educational level of the mother, and occupational status of mother, socioeconomic status, and source of information). So the following recommendation is suggested, highlight the need for excessive nutritional educational program, about diarrhea should be implemented for mothers, good sanitation and improvement of housing conditions especially water resources at arbit camp
\end{abstract}

Key words: Mothers' knowledge, Children less than five years, Internally Displaced Persons, Poor sanitation, Water contamination. Food hygiene

\section{INTRODUCTION}

Obviously diarrhea is regarded as a key cause of death in children aged less than 5 years old. Diarrhea diseases are a leading cause of morbidity and mortality among young children in low-income countries $[1,2]$. Although oral rehydration has been shown to reduce early child mortality, the diarrhea-specific mortality in children less than 5 years of age in Africa has been estimated at about 10.6 per 1,000 [3]. Young children are especially susceptible to diarrhea ailment and the common of deaths associated with diarrhea occur in South Asia and Africa. This is unfortunate since the condition can be easily treated with oral rehydration therapy $[4,5]$. Diarrhea is known as a child with watery stool for 3 or more times during a 24-hour period [6, 7]. The incidence and austerity of diarrhea are serious by lack of entree to adequate clean water and healthy disposal of human waste, insufficient nourishing practices and hand washing, poor housing conditions, and avoid of admission to sufficient and affordable health care [7]. The etiology of diarrhea must be understood to accelerate additional preventive measures. Optimal infant and young child feeding practices could prevent more than 10 percent of deaths from diarrhea and acute respiratory infections $[6,7]$. Better hygiene practices, particularly hand hygiene with cleanser and the secure disposal of waste, could reduce the incidence of diarrhea by 35 percent $[8,9]$. Diarrhea is usually a symptom of an infection in the intestinal tract, which can be caused by a variety of bacterial, viral and parasitic organisms. Infection is spread through contaminated food or drinking-water, or from person-to-person as a result of poor hygiene $[10,11]$. The occurrence of diarrhea advances in the second half of the infant's life when inborn immunity is fragile and publicity to unclean weaning foods surges $[12,13]$. Health education about significance of rehydration and feeding practices for mothers, in general are a major contributor to child morbidity and mortality [6, 14]. Oral rehydration solutions (ORS) or commercially available solutions made of appropriate amounts of sodium, potassium, and glucose should be used for rehydration if patients can consume or drink the required volumes; otherwise 
appropriate intravenous fluids may be used $[15,16]$. The most important aspect of treating diarrhea involves the resolving dehydration and replacing of lost fluid [15].

\section{MATERIAL AND METHODS}

The current study was implemented during the application of quantitative design of a descriptive study was utilized the assessment method and applied on mothers from december22 2015 to march $20^{\text {th }} 2016$. Non-probability sampling an expediency sample of (103) mothers of Internally Displaced Persons ((IDPs) at Arbit camp for following up the health status of their children, was elected for the aim of the study. A questionnaire was developed for the purpose of the study. It was encompassed of 2 parts; the first part comprises the mothers' demographic attributes and the second part evaluated the knowledge of diarrhea with (20) questions marking Correct answer or Incorrect answer Official approval was taken from the primary health care center at Arbit camp and assuring them that all information collected would be kept strictly confidential and would not be used for purposes other than research A pilot study was carried out for the period of December 10th to 20th, 2015 to determine the questionnaire reliability through the use of (Test Retest). A panel of (7) experts was involved in the determination of the questionnaire content validity. The gained data of the participant's entered in to the computer and analyzed over utilize of (SPSS 11.5); the data analyzed was preformed during the subsequent methods, which are: descriptive statistical data. Cross tap of data analysis approach such as (frequency and chisquare) were used as methods for data analysis. Test of significant with a $\mathrm{P}$ Values of $\leq 0.05$ were considered level of significance.

\section{RESULTS}

Figure (1) shows that more than half $(54.40 \%)$ of mother's among Internally Displaced Persons (IDPs) in Arbit camp are (18-25) years old.

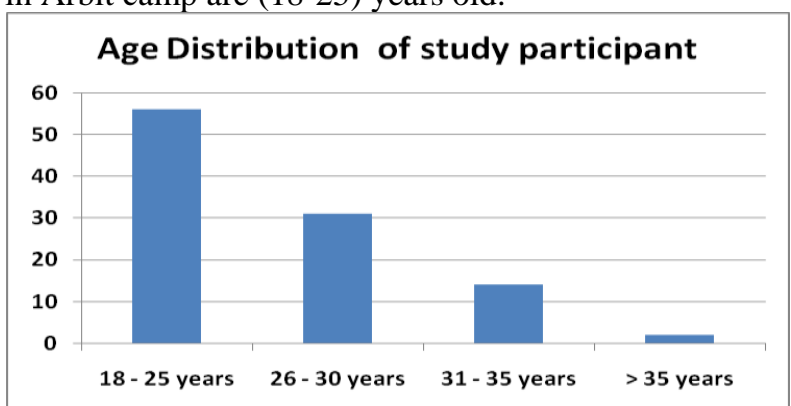

Figure (1) percentage of mother's age group

Figure (2) shows the educational level of mother's and their husbands at Internally Displaced Persons (IDPs) at
Arbit camp. Less than half $(46.60 \%)$ of mother's were illiterate and only $(32.00 \%)$ of husband read and write

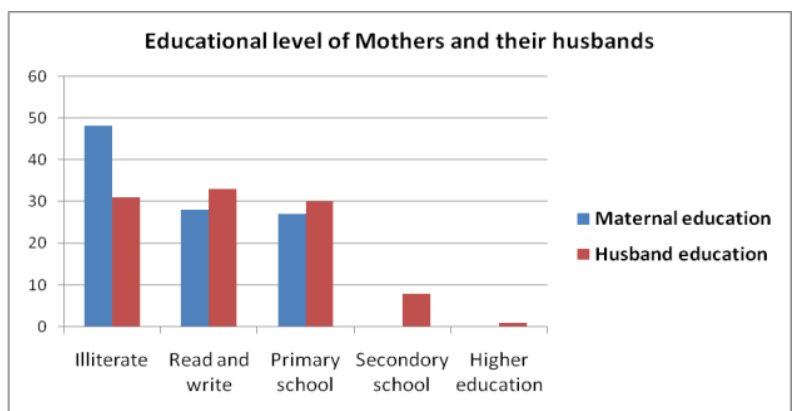

Figure (2) percentage educational level of the mother's and their husbands

figure (3) shows the percentage of maternal knowledge about causes of diarrhea among Internally Displaced Persons (IDPs) in arbit camp.

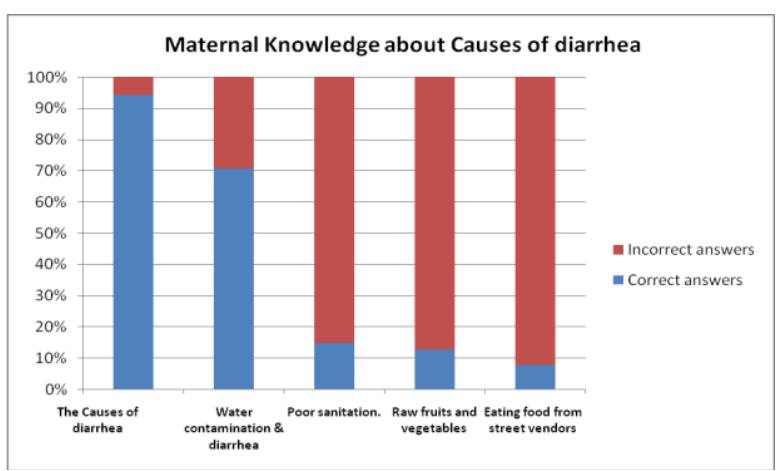

Figure (3) percentage of maternal knowledge about causes of diarrhea

figure (4) shows the percentage of maternal knowledge about diarrhea management among Internally Displaced Persons (IDPs) in Arbit camp,(32.9\%) of mothers revealed continues breast-feeding for children is best, $(53.7 \%)$ of mother shows continues formula feeding for children is good

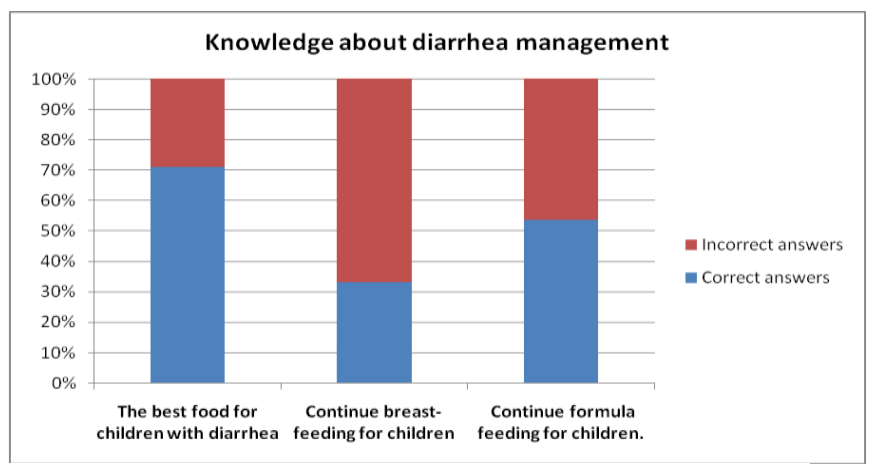

Figure (4) percentage of maternal knowledge diarrhea management 
Table 1. Distribution of the subjects (103 mothers) by their Socio-demographic attributes

\begin{tabular}{|c|c|c|c|c|}
\hline Age (Years) & Frequency & Percent & $\mathrm{P}$ value & $\begin{array}{l}\text { Significan } \\
\text { ce }\end{array}$ \\
\hline $18-25$ & 56 & $54.40 \%$ & $<0.001$ & $\mathrm{HS}$ \\
\hline $26-30$ & 31 & $30.10 \%$ & & \\
\hline $31-35$ & 14 & $13.60 \%$ & & \\
\hline$\leq 35$ & 2 & $1.90 \%$ & & \\
\hline Total & 103 & $100 \%$ & & \\
\hline Educational level of mother & Frequency & Percent & & \\
\hline Illiterate & 48 & $46.60 \%$ & 0.02 & $\mathrm{~S}$ \\
\hline Read and Write & 28 & $27.20 \%$ & & \\
\hline Primary school only & 27 & $26.20 \%$ & & \\
\hline Total & 103 & $100 \%$ & & \\
\hline Educational level of husband & Frequency & Percent & & \\
\hline Illiterate & 31 & $30.10 \%$ & $<0.001$ & HS \\
\hline Read and Write & 33 & $32.00 \%$ & & \\
\hline Primary school only & 30 & $29.10 \%$ & & \\
\hline Secondary school only & 8 & $7.80 \%$ & & \\
\hline More than secondary school & 1 & $1.00 \%$ & & \\
\hline Total & 103 & $100 \%$ & & \\
\hline Socio-economic status: & Frequency & Percent & & \\
\hline Low & 48 & $46.60 \%$ & $<0.001$ & HS \\
\hline Moderate & 51 & $49.50 \%$ & & \\
\hline High & 4 & $3.90 \%$ & & \\
\hline Total & 103 & $100 \%$ & & \\
\hline Occupational status of mother & Frequency & Percent & & \\
\hline Housewife & 102 & $99.00 \%$ & $<0.001$ & HS \\
\hline Employee & 1 & $1.00 \%$ & & \\
\hline Total & 103 & $100 \%$ & & \\
\hline Family size & Frequency & Percent & & \\
\hline$-<5 \quad$ children & 50 & $48.50 \%$ & 0.77 & NS \\
\hline$\geq 5 \quad$ children & 53 & $51.50 \%$ & & \\
\hline Total & 103 & $100 \%$ & & \\
\hline distance of water source & Frequency & Percent & & \\
\hline$<5$ minutes & 45 & $43.70 \%$ & 0.2 & NS \\
\hline $5 \geq$ minutes & 58 & $56.30 \%$ & & \\
\hline Total & 103 & $100 \%$ & & \\
\hline Number of children less than 5 years & Frequency & Percent & & \\
\hline $0-1$ child & 56 & $54.40 \%$ & 0.38 & NS \\
\hline$\geq 2$ & 47 & $45.60 \%$ & & \\
\hline Total & 103 & $100 \%$ & & \\
\hline Source of information & Frequency & Percent & & \\
\hline Media & 30 & $29.10 \%$ & 0.01 & $\mathrm{~S}$ \\
\hline Health Centers & 26 & $25.20 \%$ & & \\
\hline The physician & 12 & $11.70 \%$ & & \\
\hline All of the above & 35 & $34.00 \%$ & & \\
\hline
\end{tabular}




\begin{tabular}{|l|l|l|l|l|} 
Total & 103 & $100 \%$ & \multicolumn{2}{|l|}{} \\
\cline { 1 - 2 } $\begin{array}{l}\text { Visiting primary health care center during the antenatal } \\
\text { period }\end{array}$ & Frequency & Percent & \multicolumn{2}{|c|}{} \\
\hline Available & 49 & $47.60 \%$ & 0.62 & NS \\
\hline Unavailable & 54 & $52.40 \%$ & & \\
\hline Total & 103 & $100 \%$ & \\
\hline
\end{tabular}

Table (1) illustrate that these risk factors (age, educational level of mother, educational level of husband socio-economic status, occupational status of mother, source of information) does have an effect on diarrhea of children less than five years at Internally Displaced Persons (IDPs) Arbit camp.

Table 2 Knowledge of the subjects (103 mothers) concerning diarrhea

\begin{tabular}{|c|c|c|c|c|c|}
\hline \multirow{2}{*}{ List } & \multirow{2}{*}{ Items } & \multicolumn{2}{|c|}{ Correct answer } & \multicolumn{2}{|c|}{ Incorrect answer } \\
\hline & & Frequency & Percent & Frequency & Percent \\
\hline 1. & Knowledge about cause of diarrhea & 96 & $94.1 \%$ & 6 & $4.9 \%$ \\
\hline 2. & Water contamination is the leading cause of diarrhea & 72 & $70.6 \%$ & 30 & $29.4 \%$ \\
\hline 3. & Poor sanitation one of the leading causes of diarrhea. & 15 & $14.7 \%$ & 87 & $85.3 \%$ \\
\hline 4. & $\begin{array}{l}\text { Raw vegetables \& fruits are common causes of food-borne } \\
\text { illness). }\end{array}$ & 13 & $12.7 \%$ & 89 & $87.3 \%$ \\
\hline 5. & $\begin{array}{l}\text { Eating food from street vendors (uncovered food)caused } \\
\text { diarrhea }\end{array}$ & 8 & $7.8 \%$ & 94 & $92.2 \%$ \\
\hline 6. & The best food for children with diarrhea & 73 & $70.9 \%$ & 30 & $29.1 \%$ \\
\hline 7. & Continue breast-feeding for children with diarrhea & 27 & $32.9 \%$ & 55 & $67.1 \%$ \\
\hline 8. & Continue formula feeding for children with diarrhea. & 44 & $53.7 \%$ & 38 & $46.3 \%$ \\
\hline 9. & Diarrhea and causes of dehydration in children & 41 & $50 \%$ & 41 & $50 \%$ \\
\hline 10. & (Covered container) used for water transportation. & 97 & $96 \%$ & 4 & $4 \%$ \\
\hline 11. & Good scrubbing of drinking water tanks. & 40 & $39.6 \%$ & 61 & $60.4 \%$ \\
\hline 12. & Boiling of drinking water & 39 & $38.6 \%$ & 62 & $61.4 \%$ \\
\hline 13. & Using chlorine for drinking water & 22 & $21.8 \%$ & 79 & $78.2 \%$ \\
\hline 14. & Food hygiene better before preparing food. & 96 & $94.1 \%$ & 6 & $5.9 \%$ \\
\hline 15. & Hand washing before handling food. & 50 & $48.5 \%$ & 53 & $51.5 \%$ \\
\hline 16. & Cleaning of vegetables and other foods & 53 & $51.5 \%$ & 50 & $48.5 \%$ \\
\hline 17. & Cleaning of cooking and eating utensils. & 8 & $7.8 \%$ & 95 & $92.2 \%$ \\
\hline 18. & Information about proper food hygiene & 94 & $91.3 \%$ & 9 & $8.7 \%$ \\
\hline 19. & Proper home management of diarrhea & 74 & $74 \%$ & 26 & $26 \%$ \\
\hline 20. & Using an Oral rehydration solutions package. & 71 & $68.9 \%$ & 32 & $31.1 \%$ \\
\hline
\end{tabular}


The level of mother's knowledge regarding diarrhea was measured through (20) questions, marking true or false for each question. Table 2 shows that (94.1\%) of mothers has knowledge about causes of diarrhea among Internally Displaced Persons (IDPs) in Arbit camp. More than half $(70.6 \%)$ water contamination, $(14.7 \%)$ poor sanitation, (12.7\%) raw vegetables and fruits, $(7.8 \%)$ eating food from street vendors, more than half $(70.9 \%)$ revealed that the best food for children with diarrhea, $(32.9 \%)$ of mothers revealed continues breast-

\section{DISCUSSION}

Diarrhea diseases are amidst the most frequent childhood illnesses and driving cause of avoidable death, particularly between children less than 5 in developing countries [17]. Diarrhea consequences in huge losses of water and electrolytes, particularly potassium and sodium, and habitually is complicated by severe systemic acidosis [18]. Additionally, 4.9 children per 1000 per year decease as a effect of diarrhea ailment in the first 5 years of life in developing countries [19]. When they asked about cause of diarrhea, all of them unless six mothers $(94.1 \%$ knew cause of diarrhea, because the utmost public cause of acute diarrhea is a viral infection [20]. While, other causes comprise bacterial infections; side effects of antibiotics and infections not associate with the gastrointestinal system. However, there are numerous less public causes of diarrhea. Bacterial, viral and parasitic infections are all infectious [21]. Water pollution is a major global problem which requires ongoing evaluation and revision of water resource policy at all levels (international down to individual aquifers and wells). It is the leading worldwide cause of deaths and diseases [22, 23], so that it accounts for the deaths of more than 14,000 people daily [23]. Fortunately, (70.6\%) of mothers knew that. $(14.7 \%)$ of mothers had information regarding poor sanitation one of the leading causes of diarrhea. having adequate latrines. decrease contact between host and causative organisms of diarrhea. This finding was similar to study [24].

Mothers had low knowledge regarding eating raw vegetables and fruits because only $(12.7 \%)$ of them knew that raw vegetables and fruits are common causes of food-borne illness. Most camps either don't allow migrants share of agriculture, or there isn't adequate rainfall or water to do so. Consequently, emigrants have established innovative instruments for obtaining more nourishment. [25]. Recycling in itself is a risky procedure and also takes part to the attendance of a black market in many immigrant camps. However, low knowledge about eating food from street vendors cause diarrhea seen among (7.8\%) the mothers in the present study. These ready to-eat foods and drink beverages are intended and/or sold by sellers essentially in the streets or other proper public places such as around places of hospitals, schools, work and bus terminals, are commonly prepared and sold under in sanitary conditions, with constrained entree to safe water, hygienic services, or refuse disposal facilities. Nevertheless $(70.9 \%)$ of participants identified that feeding for children is best, $(53.7 \%)$ of mother show continues formula feeding for children is good,(50\%) of mothers knew diarrhea cause dehydration in children, Covered container used for water transportation, Food hygiene better before preparing food, Information about proper food hygiene(96\%, 94.1\%, 91.3 respectively),(74\%) of mothers had information about proper home management of diarrhea, more than half (68.9\%) has information about using an oral rehydration solutions package for diarrhea treatment.

continue to be fed small meals throughout the day. World Health Organization recommends a kid with diarrhea constantly to be nourished. Sustained nourishing hustles the recovery of normal intestinal function. Regarding the importance of breastfeeding of babies with diarrhea, $(32.9 \%)$ of partakers said that they would breastfeed their child if they infected with diarrhea. It is still a big issue that dietary forms through acute diarrhea disease isn't acknowledged to many mothers in the present study, as it has a main impact on recover from diarrhea [26]. Fifty three percent of the mothers in the present study has knowledge regarding formula feeding. Formula-fed babies should continue to take their usual formula, while they have diarrhea. Through a diarrhea incident, water and electrolytes (bicarbonate, sodium, potassium and chloride) are lost during watery stools, vomiting, perspiration, urine and breathing. Dehydration incidences when these losses are not substitutes [27]. The baby may be having diarrhea if they have unexpected increase in the number of bowel movements. Stool with a very bad smell may also be a sign of diarrhea if the diarrhea is very severe or notice signs of dehydration [28]. Respectively, (96\%) of mothers has mentioned that the covered container used for water transportation .because collected water is more susceptible to pollution during transportation and storage which increase risk of diarrhea diseases .This finding is in agreement with study in Kenya [29].

It is scrubbing the internal surfaces of the tank. Use a mixture of detergent and hot water (household laundry soap powder will do) to scrub and clean all internal surfaces of the tank. But, in the present study only (39.6) of mothers knew that and more than two-third of them could not identify that; this may be attributed to their disorientation about good scrubbing of drinking water tanks. When the mothers asking what they will do for making drinking water safe, one-quarter $(38.6 \%)$ of them described that the responsibility for making drinking water safe falls to community residents by default. The traditional emergency prevention measure, boiling the water, is economically and environmentally unsustainable [30]. It takes a kilogram of firewood to bring a liter of water to boil for a minute [3], and a person requires a minimum of $2 \mathrm{~L}$ of drinking water per day [31]. Alternatives to fuel wood, such as kerosene and other fossil fuels are expensive and also pose environmental hazards [27, 20]. Mothers had low knowledge regarding using chlorine for drinking water, because only $(21.8 \%)$ of them knew that chemical disinfectants are a practical alternative to boiling, although only the safest and least expensive disinfectants are suitable for household use in the developing world. Chlorine and filtering, the most commonly used 
disinfectant in water treatment plants, is hazardous, and impractical. However, sodium and calcium hypochlorite are relatively safe [32]. When added to water in tightly covered containers, volatilization is minimal and hypochlorite disinfectants provide residual protection for many hours to days [33]. The majority of the mothers (94.1\%) knew that food hygiene better before preparing food. Good food hygiene isn't just something for restaurants to worry about. It's important to know how to prepare food safely and hygienically in the home too. Before making nourishment preparation, hands, equipment, clothes and kitchen surfaces are most be clean.

Hand-hygiene before making food is a mainly significant opportunity to inhibit childhood diarrhea and it is the best mechanism when it is become of a package of behavior change interventions [34]. Washing hands with detergent can decrease the hazard of diarrhea ailments by $(42-47 \%)$ [35]. food-hygiene practices of mothers have an effect on the spread, of diarrhea among children ,cutlery (like knives and other cutting apparatuses) can be utilized for nourishment preparations in a kitchenette and as intake utensils when eating [36]. Both of forks and spoons are other cutlery kitchen and eating utensils. Unfortunately, in the current study more than two-third (92.2\%) of partakers didn't recognize that. Therefore poor knowledge mothers requires more conscious about washing of a kitchen utensil. Correspondingly, (91.3\%) of mothers had information about proper food hygiene; Good food hygiene isn't just something for restaurants to worry about. It's important to know how to prepare food safely and hygienically in the home too. In both developed and developing countries Food transmitted ailment stays a serious and enormous problem, causing excessive human suffering and important economic losses. Up to $1 / 3$ of the inhabitants of developed countries may be affected by illnesses, which borne annual through food-borne, then the problem is possible to be even more occurrence in developing countries, every year an estimated 2.2 million people killed because of food and water-borne diarrhea illnesses. (74\%) of participants identified the benefit of proper home management of diarrhea through the use of oral rehydration solution[37] This was because culturally, mothers used their treatment at home and wait many days before visiting the health facility. These results are more or less comparable with the study conducted by [37], in Egypt (a developing country) which showed that in the past ( $2 \mathrm{wks})$ of diarrhea episodes.

\section{CONCLUSION}

The study demonstrates that (poor sanitation, raw vegetables \& fruits, eating food from street vendors, hand washing, using chlorine for drinking water ) were the five major causes of diarrhea diseases in children aged under five years old. These risk factors (occupational status of mother, socio-economic status of mother; educational level of husband and age of mothers ) have an effect on the diarrhea diseases, however (family size, distance of water source, number of children less than 5 years, visiting primary health care center during antenatal period) does not an effect on the causes of diarrhea diseases), personal communication, concentrated group discussion, and home visits accomplished during volunteers produced an important enhancement in mother's knowledge with respect to household healthcare for children less than the age of five with diarrhea ailment, The results of this study can be useful in the development of future interventions, effective health education can only be provided on the basis of an accurate understanding of prevailing knowledge aiming to reduce diarrhea appearance in similar camps

\section{ACKNOWLEDGMENT}

We would like to express our thanks to the work of (Dr. Nawroz A. Tahir) for his valuable guidance and review of the article. We must also acknowledge the staff of the Preventive Directorate in Sulaimani city for their cooperation and all staff of the health center in Arbit camp, who gave so freely of their time in facilitating the study.

\section{REFERENCES}

[1] AB Patel, R Ovung, NB Badhoniya, MJ Dibley. Risk factors for predicting diarrheal duration and morbidity in children with acute diarrhea. Indian J Pediatr. 2012; 79:472-477.

[2] CS Yilgwan, SN Okolo. Prevalence of diarrhea disease and risk factors in Jos University Teaching Hospital, Nigeria. Ann Afr Med. 2012; 11:217-221.

[3] B Banerjee, S Hazra and D Bandyopadhyay, Diarrhoea management among under fives. Indian Pediatric. 2004; 41 (3): 60-255.

[4] P Chongbanyatcharoen. Acute diarrhea's recommendations on oral rehydration therapy and feeding. Med Assoc Thai. 2005;88(Suppl 1):S30-4.

[5] K. Yassin, "Morbidity and risk factors and diarrhea diseases among under-five children in rural Upper Egypt," Journal of Tropical Pediatrics, vol. 46, no. 5 , 2000, pp. 282-287.

[6] World Health Organization (WHO), Integrated Management of Childhood Illness, 2010.

[7] H Salmalin, S Omidva, ME Douki. Maternal knowledge and attitude on prevention and care toward diarrhea disease in under five years old children in Babol 2001. J Babol Uni Med Sci. 2004; 24(7):81-7.

[8] ORC Central Statistical Authority and Macro.Ethiopia Demographic and Health Survey 2011, Addis Ababa, Ethiopia, 2011.

[9] WHO World Health Organization, World Water .Day Report, WHO, Geneva, Switzerland, 2000.

[10] ME Motlagh, A Heidarzadeh, H Hashemian, M Dosstdar. Patterns of Care Seeking During Episodes of Childhood Diarrhea and its Relation to Preventive Care Patterns: National Integrated Monitoring and Evaluation 
Survey (IMES) of Family Health. Islamic Republic of Iran. Int J Prev Med. 2012; 3(1):60-7.

[11] K. Oadi and M. Kuitunen, "Childhood diarrhea morbidity in the Accra Metropolitan Area, Ghana: socioeconomic, environmental and behavioral risk determinants," Journal of Health and Population in Developing Countries, Article ID 17646, 2005, pp. 3346.

[12] C. L. Fischer Walker, I. Rudan, L. Liu et al., "Global burden of childhood pneumonia and diarrhoea," The Lancet, vol. 381, no. 9875, 2013, pp. 1405-1416.

[13] A. G. Yohannes, K. Streatfield, and L. Best, "Child morbidity patterns in Ethiopia," Journal of Biosocial Science, vol. 24, no. 2, 1992, pp. 143-155.

[14] Federal Ministry of Health, National Strategy for Child Survival in Ethiopia, Family Health Department, Addis Ababa, Ethiopia, 2005.

[15 A Chiabi,.., F Monibenimp,., J. B Bogne,., V Takou,.., \& Tetanyee. Current approach in the management of diarrhea in children. Clinical mother and child health ,2010,7(1), 1243-1251.

[16] Center for Disease Control, Guidelines for the Management of Acute Diarrhea, Department of Health and Human Services in United States, 2008.

[17] J Gascon, M Vargas, D Schellenberg, H Urassa, C Casals, E Kahigwa, et al. Diarrhea in children under 5 years of age from Ifakara, Tanzania: a case-control study. J Clin Microbial. 2000; 38:4459-62.

[18] United Nations Children's Fund (UNICEF) End Decade Databases. World Summit for Children on Diarrhea disease. Review of decade progress 2000.

[19] HM Haroun, MS Mahfouz, El Mukhtar M, Salah A. Assessment of the effect of health education on mothers in $\mathrm{Al}$ Maki area, Gezira state, to improve homecare for children under five with diarrhea. J Family Community Med. 2010; 17(3):141-6.

[20] S Fuchs and C Victora. Risk and prognostic factors for diarrheal disease in Brazilian infants: a special case-control design application, Cad. Saúde Pública, Rio de Janeiro journal, (2002); 18(3):773-782.

[21] T. Gerald, O. Keusch, and B. Alok, Disease Control Priorities in Developing Countries, World Bank, Washington, DC, USA,2001.

[22] H Pink, Daniel. "Investing in Tomorrow's Liquid Gold". Yahoo. Archived from the original on April 23, 2006.

[23] West, Larry ."World Water Day: A Billion People Worldwide Lack Safe Drinking Water". About.com 2006-03-26.
[24] L Fewtrell, B Kaufmann, D Kay, W Enanoria, L Haller., J Colford. Water, sanitation, and hygiene interventions to reduce diarrhoea in less developed countries. A systematic review and meta-analysis. Lancet Infectious Disease 2005. 5:42-52

[ 25] B Bruijn,. "Human Development Research. The Living Conditions and Well-being of Refugees." 2009 pp. 25.

[26] N Leon-Cava, S Lutter, J Ross, L Martin. quantifying the benefits of breastfeeding: A summary of the evi-dence. Pan American Health Organization, Washington DC, 2002.

[27] SC Porter, GR Fleisher, IS Kohane, KD Mandl. The value of parental report for diagnosis and management of dehydration in the emergency department. Ann Emerg Med. 2003; 41(2):196-205.

[28] JN Friedman, RD Goldman, R Srivastava, PC Parkin. Development of a clinical dehydration scale for use in children between 1 and 36 months of age. J Pediatr. 2004; 145(2):201-207.

[29] A Ghasemi, _A Talebian, $N$ Alavi and G Mousavi.Knowledge of Mothers in Management of Diarrhea in Under-Five Children, in Kashan, Iran ,Nursing and Midwifery Studies, (2013),1(3): 62-158.

[30] L Roberts, Y Chartier, O Chartier, G Malenga, Toole M, Rodka H. Keeping clean water clean in a Malawi refugee camp: a randomized intervention trial. Bull World Health Organ. 2001;79:280-287.

[31] A El-Gilany and S Hammad .Epidemiology of diarrhoeal diseases among children under age 5 years in Dakahlia, Egypt. East. Mediterr. Health J (2005). 11 (4):75-762.

[32] PK Jensen, JH Ensink, G Jayasinghe, W van der Hoek, S Cairncross, A Dal sgaard .Effect of chlorination of drinking-water on water quality and childhood diarrhoea in a village in Pakistan. J Health Popul Nutr, 2002:. 21:26-31

[33] RE Quick, A Kimura, A Thevos, M Tembo, I Shamputa, L Hutwagner, E Mintz Diarrhoea prevention through household-level water disinfection and safe storage in Zambia. Am J Trop Med Hyg, 2002: 66(5): 584-9

[34] V Curtis, S Cairncross. Effect of washing hands with soap on diarrhea risk in the community: A systematic review. Lancet Infect Disease 2003; 3:27581 .

[35] . R Ejemot, J Ehiri, M Meremikwu, J Critchley.Hand washing for preventing diarrhoea. Cochrane Database Syst Rev 2008. 23:CD004265.

[36] R Stanwell-Smith, S Bloomfield. Milano: Arti Grafiche Bazzi;. The hygiene hypothesis and 
implications for home hygiene (A report commissioned by the International Scientific Forum on Home Hygiene), 2004 p. 40.

[37 AH EI Gilany, Hammeds Epidemiology of diarrhoeal diseases among children under 5 years of age in Dakahlia, Egypt. Eastern Mediterranean Health Journal. 2005; 11:4. ad received ORS and (75\%) had received antibiotics. 